\title{
Quando olhar é fazer: do espectador convidado ao espectador ausente
} When looking is doing: from the invited spectator to the absent one

\section{Verônica Veloso}

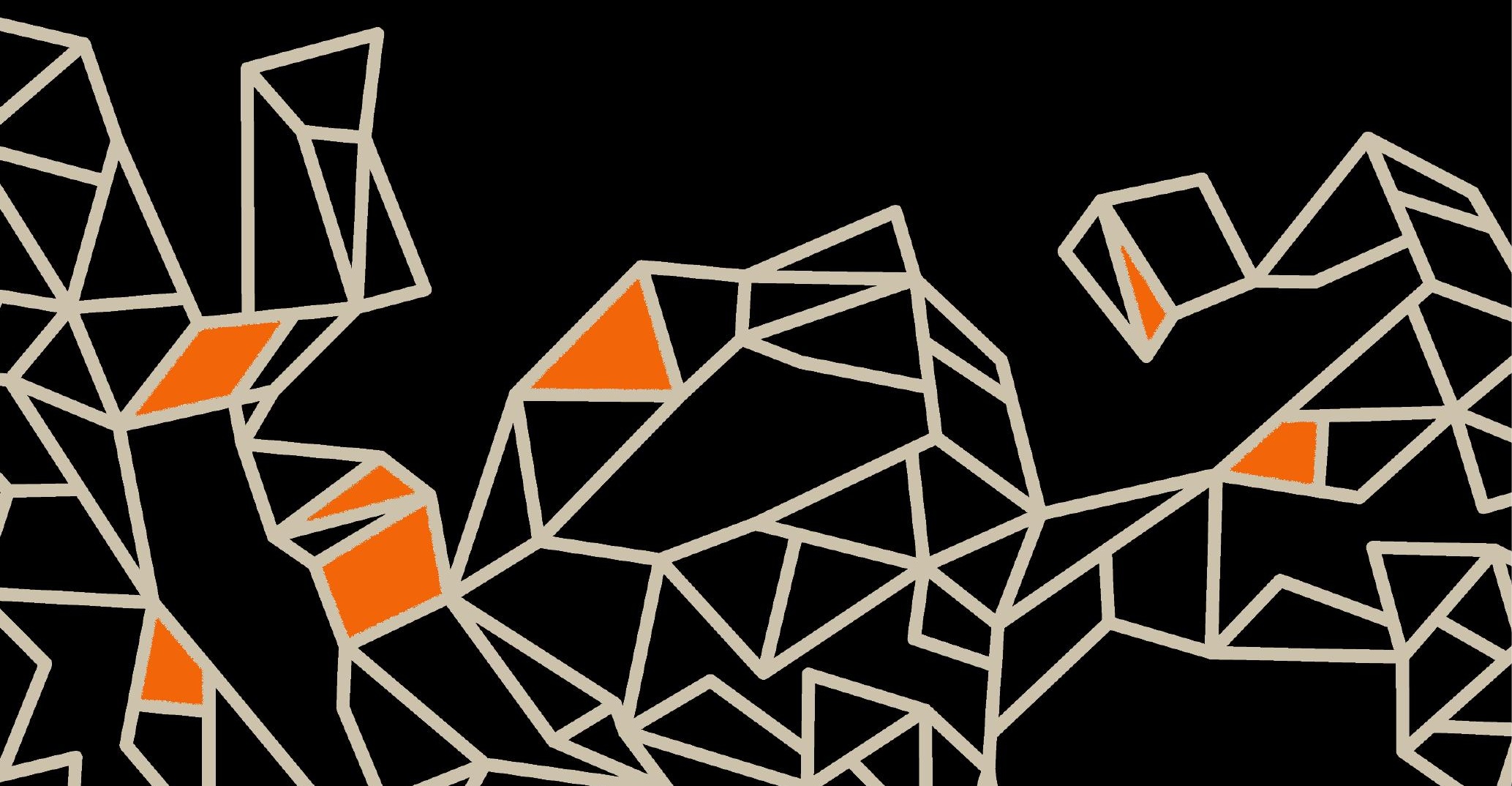




\section{Resumo}

O artigo propõe uma reflexão sobre o estatuto do espectador na cena performativa contemporânea e os resquícios dessa figura no campo da performance. Possíveis categorias para se pensar o espectador são identificadas em alguns experimentos teatrais e performativos fundados no ato de caminhar no contexto urbano. Para além do espectador convidado são considerados também os passantes e aqueles que acessam a performance por intermédio de outras materialidades, a fotografia por exemplo. A ação passa a prescindir da presença do espectador, uma vez que se dirige para a câmera, e esse deslocamento nem sempre valoriza o documento em detrimento do corpo, mas necessariamente o inclui como constitutivo do ato performático.

Palavras-chave: Espectador, Contexto urbano, Corpo, Fotografia.

\section{Abstract}

This paper proposes a reflection on the statute of the spectator in contemporary performative scene and the traces of this figure in the performance field. Theatrical and performative experiments, founded in the act of walking in urban context, identify different categories to think about the spectator. Beyond the invited spectator we may also consider the bystanders and those who access the performance through others materialities, such as photograph. The action no longer needs the spectator's presence, since now it addresses itself to the camera. However, this shift does not always value the document at the expense of the body, but includes it necessarily as a component part of the performative act.

Keywords: Spectator, Urban context, Body, Photo.

A questão do espectador está diretamente relacionada ao seu atual estatuto dentro da cena teatral contemporânea e também da performance. Se em uma acepção mais convencional do teatro, o espectador sabe exatamente como deve se comportar, por já ter sido disciplinado para isso, nas modalidades cênicas deambulatórias que ocupam o espaço público, o corpo do espectador passa a ser interpelado de outras formas. No primeiro caso, há cadeiras para acomodar o público dentro de um edifício teatral, onde todos devem permanecer em silêncio. No segundo, o espectador precisa se deixar 
levar até entender o que cabe a ele, onde deverá se posicionar, em que momentos deverá caminhar e como se dará sua interação com cada uma dessas ações. Isso não significa que não haja exceções dentro dos edifícios teatrais, pois cada vez mais os artistas têm explorado outros paradigmas para a relação que se estabelece com o público. O desconforto do espectador diante da cena, no entanto, é contemporâneo das dissoluções dos estatutos teatrais. Conforme Silvia Fernandes, é justamente a indefinição de seu estatuto epistemológico uma das características mais marcantes da cena contemporânea, que, conforme a pesquisadora, passa por uma "crise de identidade" (2011, p.11). Portanto, não é apenas o espectador que passa por uma revisão de seu estatuto na contemporaneidade, as noções de encenação e de obra de arte também sofrem uma profunda revisão, capaz de reinventar os modos de fazer e de usar a arte dos nossos dias.

\section{O espectador como princípio ativo}

O espectador teria se transformado no "princípio ativo" da obra, afirma Sophie Lucet (2013), que se interessa pela memória deste ao discutir as criações e os pensamentos de artistas de estéticas muito diferentes entre si, como Jean Vilar, Jérôme Bel e Joël Pommerat. Tomo tal metáfora emprestada para refletir sobre a inclusão do espectador como coautor, agente e mesmo pesquisador dessas experimentações artísticas no contexto urbano. A ideia de transformá-lo em princípio ativo da ação parece servir muito bem para refletir sobre os modos de operar propostos a ele em diferentes modalidades cênicas. Isso não significa afirmar que ele seja ativo em detrimento de uma possível passividade de outro espectador, que permanece sentado ao longo de sua fruição artística. Associar a "atividade" (em oposição à passividade) ao deslocamento físico reforça a dicotomia corpo e mente, como se a mente de um corpo em estado de pausa não funcionasse. Nesse caso, atividades como a leitura, a meditação, o estudo ou uma ida ao cinema não poderiam ser consideradas "ativas" para o espectador contemporâneo. No mesmo sentido, Jacques Rancière aponta que ser ativo ou passivo diz respeito a divisões sociais antes de serem tomadas como qualidades para as ações do corpo. 
Durante séculos e milênios, a humanidade foi dividida em homens ativos e homens passivos. Homens ativos eram aqueles que não tinham necessidade de trabalhar para ganhar sua vida. $E$ os passivos não eram pessoas que permaneciam de braços cruzados, mas, ao contrário, que produziam, se reproduziam e ganhavam sua vida, fechados no universo da necessidade imediata. Eu tentei recolocar o que parece ser evidente: a oposição ativo/passivo se inscreve em uma partilha do sensível, o que quer dizer que são posições sociais e simbólicas antes de serem posições reais do corpo. $E$ tentei, também, dizer que o que se passa quando alguém vê um espetáculo, um filme ou não importa qual coisa... não pode se definir em termos de passividade. Olhar é uma atividade. (RANCIĖRE, 2013, p. 10, tradução da autora).

Desse modo, afirmar que o espectador pode ser transformado em "princípio ativo" da ação nada tem a ver com ser ativo ou passivo. O que pretendo afirmar é que o espectador pode ser considerado, metaforicamente, como um dos elementos (ou substâncias) que consegue ter ação sobre o acontecimento cênico (ou organismo). Assim como um medicamento, uma planta ou um alimento tem diversas substâncias em sua composição e apenas uma ou algumas delas podem agir sobre o organismo, o espectador seria esse princípio ativo do acontecimento cênico, pois é dada a ele a capacidade de exercer determinado feito, definição de rumo ou até mesmo reunir em seu corpo uma quantidade específica de informações que, juntas, se configuram como a experiência artística em si.

Muitos autores têm se voltado ao estudo do espectador na contemporaneidade. Jacques Rancière, cuja intenção inicial era investigar o espetáculo na sua acepção mais ampla, ideológica, dedicou-se posteriormente ao teatro, tornando-se uma referência sobre o assunto no campo das artes. Segundo ele, a emancipação do homem acontece quando se questiona a oposição entre agir e olhar, e assim como não cabe ao professor transmitir conhecimentos, "o mesmo ocorre com a performance. Ela não é a transmissão do saber ou do sopro do artista ao espectador" (RANCIÈRE, 2012, p. 19). O autor não defende, entretanto, uma condição "participativa" para o espectador, no sentido específico que se dá a uma arte considerada "interativa", o que enfatiza é a atividade intrínseca ao espectador, "o papel de intérprete ativo", um sujeito capaz de tecer relações com seus próprios refe- 
renciais, sejam eles quais forem, e de elaborar traduções, ou seja, de construir suas próprias narrativas.

Nicolas Bourriaud, por sua vez, afirma que a aura da arte atual deslocou-se para o público, pois ela "leva em conta, em seu processo de trabalho, a presença da microcomunidade que irá acolhê-la. Assim, uma obra cria uma coletividade instantânea de espectadores-participantes, seja em seu modo de produção ou no momento de sua exposição" (1998, p. 82). Atento à importância do encontro e da dimensão relacional presente nas obras atuais, o autor recorre a exemplos bastante significativos nos quais os artistas apelam ao senso de responsabilidade dos espectadores, convocando seus corpos como forma de exposição da realidade. Retomo, portanto, dois exemplos oferecidos por Bourriaud que colocam o corpo do espectador como disparador da obra. Esse tipo de arte "não deriva da simples percepção ocular: o que o espectador traz é todo o seu corpo, sua história e seu comportamento, e não mais uma simples presença física abstrata" (Ibid., p. 83).

No primeiro exemplo, o cubano Felix Gonzalez-Torres delimitou um quadrilátero de luzes acesas e disponibilizou um par de walkmans para que os espectadores pudessem dançar, em aparente silêncio, no meio da galeria (Untitled, galeria Jennifer Flay, Paris, 1993). No segundo, o dinamarquês Jens Haaning (Turkish Jokes, 1994), criou uma ação na qual transmitia histórias engraçadas em turco, por alto-falantes, em uma praça de Copenhague, essa ação concentrou na praça dinamarquesa uma pequena comunidade de estrangeiros que saiu de sua situação de exílio por alguns instantes. Em ambos os casos, os artistas oferecem dispositivos para serem usados pelos espectadores. No primeiro exemplo, o espectador é quem decide expor-se ou não, colocar ou não o seu corpo em estado de dança no meio da galeria, sozinho ou acompanhado. Mesmo dançando sozinho, a presença do segundo walkman, em espera, está disponível para alguém ausente. Esse modo de inscrever mensagens nos fatos é uma marca desse artista que apostou com frequência em duplas de objetos (dois relógios, em sua obra mais conhecida). Certamente, muitos não se dispuseram a usar o walkman e exibir seu corpo dançante, no entanto essa obra dependia não só do corpo do espectador para ser acionada, mas também de seu tempo. É ele quem decide o tempo de permanência não diante, mas na obra, como princípio ativo da ação. O espec- 
tador tem poder de decisão, de execução e de fruição. Aquele que observou o espaço vazio com dois pares de walkman num quadrado luminoso viu uma instalação, enquanto cada pessoa que resolveu dançar criou sua própria narrativa a partir de sua experiência.

Nos dois exemplos, os corpos dançando ou reunidos em torno dos alto-falantes constituem-se como eventos a serem também observados. A microcomunidade turca, reunida numa praça em Copenhague, rindo e desfrutando de histórias que somente ela entende, evidencia a presença de imigrantes numa esfera mais ampla, na qual são frequentemente mantidos longe dos holofotes. Se o áudio fosse emitido em um local sem a presença dessas pessoas, nada aconteceria, pois não haveria o encontro. As histórias isoladas, nesse caso, não configuram a obra, uma vez que ela só acontece quando essa microcomunidade é colocada em destaque e observada por outros cidadãos.

Nas palavras de Bourriaud: "o espectador, então, oscila entre o papel de consumidor passivo e o de testemunha, associado, cliente, convidado, co-produtor, protagonista" (Ibid., p. 81). Assim sendo, mais importante do que responder à pergunta: "que espectador é esse?", seria questionar, o que é proposto a ele? Observando o modo de organizar esteticamente dos artistas, vale refletir sobre o alerta de Bourriaud, para quem "as atitudes se tornam formas" e "as formas induzem modelos de sociabilidade".

\section{Aquele que passa por mim: o espectador em desloca- mento}

Ao observar diferentes modalidades artísticas fundadas no caminhar, noto uma progressiva dissolução da figura do espectador em diferentes cenas teatrais contemporâneas. O mesmo acontece no campo da performance, cujas ações frequentemente são endereçadas para a câmera em detrimento da busca por um ideal de convivência associado ao encontro presencial com o espectador. Nos casos analisados ao longo de minha tese de doutorado (VELOSO, 2017), tanto as experimentações cênicas quanto as performances se inscrevem na cidade, o que faz com o que elas sejam quase sempre observadas por alguém. $\mathrm{O}$ que entra em jogo nessas experimentações urbanas é 
o coeficiente de visibilidade produzido em cada criação, pois a cidade não se esvazia para que determinada ação aconteça. Alguns artistas, entretanto, optam por agirem tão discretamente pelas ruas que se tornam visíveis apenas posteriormente. Nesse sentido, apresentarei possíveis categorias para a atividade do espectador, sem no entanto pretender classificá-los definitivamente, como se cada um pudesse acessar essas criações apenas por um desses modos. Ao contrário, o mesmo espectador poderá transitar por tais categorias, pois elas se configuram de maneira porosa, e não estática, dependendo do momento em que ele observa uma ação.

Seria possível, portanto, destacar pelo menos três categorias para a atividade do espectador: o convidado ou deliberado (alguém que foi convidado para a apresentação previamente e, por isso, já organizou sua percepção para o encontro ficcional), o passante ou fortuito (pedestre mergulhado na realidade, que provavelmente caminha pela cidade com algum objetivo e tem seu fluxo interrompido pelo evento) ${ }^{1}$, e o espectador ausente ou virtual (aquele que tem acesso ao acontecimento cênico mesmo sem tê-lo presenciado; pela internet, ele encontra fotografias, vídeos e narrativas produzidas a partir dos eventos).

Uma atriz conduz apenas dois espectadores por vez, sempre portando uma mala vermelha. Em alguns pontos do percurso, a atriz condutora é substituída por outra, que também carrega uma bagagem ou bolsa vermelha. Além de caminhar a pé, a dupla de espectadores cumpre partes do trajeto de metrô, de trem e de carro, enquanto ouve uma trilha sonora. De fones de ouvidos ao longo de toda a ação, a experiência resume-se à observação da cidade a partir de determinadas provocações lançadas pelos artistas d'OPOVOEMPÉ aos seus convidados. Trata-se de O farol (2012), experimento cênico apresentado ao longo de uma trajetória que sai da região da Berrini e vai até a estação de trem de Presidente Altino, em São Paulo (2012).

Um grupo de pessoas segue uma mulher loira pelas ruas de uma periferia parisiense. A mulher parece fugir do grupo, que se desloca rapidamente para não perdê-la de vista. Todos os integrantes usam fones de ouvido, por onde ouvem os supostos recados deixados por diferentes pessoas na secre-

1 Philip Auslander considera esse espectador passante desinformado, pois encontra-se ao acaso no mesmo espaço-tempo da ação. 
tária eletrônica dela. Aparentemente, essa mulher foge da vida que leva e com a qual já não mais se identifica. Inesperadamente, o grupo depara-se com outro grupo, que, por sua vez, também segue uma mulher loira, usando um chapéu muito parecido com o da primeira. Trata-se de No visa for this country, uma criação da Cie Sous X (2014).

Uma mulher caminha pelas ruas de diferentes cidades do Brasil (além de Buenos Aires) vestida com uma roupa de grama artificial, cobrindo todo o corpo, inclusive o rosto. Ela caminha descalça e carrega um regador de água, molhando o próprio corpo, os pés ou o chão por onde pisa. Também molha as plantas que encontra pelo caminho e se deita em alguns lugares, chegando a se camuflar sobre um pedaço de grama real. Essa mulher é a performer Maicyra Leão, em Experimentos Gramíneos, realizados entre 2006 e 2016.

Outra mulher caminha de olhos fechados pelas ruas, tocando tudo que encontra pela frente. Muitas vezes, toca as fachadas das casas, outras, as pessoas. Frequentemente é conduzida por algum desconhecido, que a ajuda a atravessar a rua ou a convida a molhar seus cabelos numa fonte. Toco Tudo faz parte da série Precários, criada por Eleonora Fabião e realizada por ela entre 2012 e 2014 em diferentes cidades.

Um homem caminha pela cidade de Praga em 1977 até encontrar o momento adequado para tocar ligeiramente alguém desconhecido. Esse contato físico ínfimo e efêmero com passantes anônimos é uma reação a um momento político de forte cerceamento de liberdades, no qual era ilegal tocar-se publicamente. Esses toques sutis entre dois passantes são registrados em fotografias. Contact foi realizada por Jiri Kovanda.

Uma mulher caminha pelas ruas de Nova York fotografando homens que a assediam pela rua. A câmera converte-se em arma, como se, ao fotografar, a artista assaltasse o assediador, invertendo sua posição dentro do jogo. Embora algumas pessoas presenciem essa ação, ela só se converte em arte quando as fotos são expostas em uma galeria, com tarjas brancas escondendo os olhos dos homens fotografados e com legendas contando o que cada um deles disse à artista ao assediá-la verbalmente. Fully Automated Nikon é uma performance de Laurie Anderson de $1973^{2}$.

2 Essa proposta inspirou o Coletivo Teatro Dodecafônico a criar Spray de Pimenta, em 2016, uma ação ao alcance de toda e qualquer mulher que caminha pelas ruas de uma cidade. 
Em 1969, outra mulher caminha pelas ruas de Viena levando seu companheiro para passear pela coleira. Ele anda de quatro, como se fosse seu cão, e ela porta um casaco de pele. Toda a ação é documentada por fotografias, de modo que a reação dos passantes também figura nas imagens selecionadas para compor um portfólio. Trata-se de Portfolio Doggedness, composto por VALIE EXPORT ${ }^{3}$, da qual participou Peter Weibel.

Um homem caminha pelas ruas da cidade do México portando uma bereta de 9 milímetros carregada na mão direita, em 4 de novembro de 2000. Nenhuma pessoa que passa por ele sabe que se trata de uma performance, a não ser pela presença de outro homem registrando discretamente a ação em vídeo. Após 12 minutos, o percurso é interrompido por dois policiais que, depois de deterem o performer, são convencidos por ele a participarem do remake da ação, como se figurassem num filme de aventura. Trata-se de Reenactement, performance realizada por Francis Alÿs e registrada duplamente por Rafael Ortega.

Esses exemplos são representativos de um deslocamento das funções e das ações atribuídas aos espectadores nos últimos cinquenta anos. Dentre as ações citadas, apenas duas contam com espectadores convidados: $O$ farol e No visa for this country. Não por acaso, tratam-se dos dois exemplos mais diretamente relacionados ao campo do teatro, ainda que, na criação d'OPOVOEMPÉ, as atrizes não assumam nenhum papel, nem se inscrevam em uma ficção. Elas são condutoras do público e proponentes de uma exploração poética e reflexiva sobre o espaço público e a mobilidade urbana. Os espectadores, por sua vez, assumem o papel de atuadores sutis, relacionando-se apenas visualmente com os atores. A ação decorrente dessa proposta permanece invisível aos olhos da cidade. Nesse caso, é a teatralidade presente no cotidiano, no modo de olhar os espaços vividos que é colocada em jogo. No segundo exemplo, o espectador é convidado a seguir o chapéu retratado em uma foto que recebe ao chegar ao ponto de encontro. Uma atriz aparece portando o chapéu da foto; ela está em fuga e assume a personagem central da trama até o momento em ela é desdobrada (o público se depara com outra atriz com chapéu semelhante, sendo seguida por um público outro)

3 Nome artístico da performer que compôs o próprio nome como um logotipo, por isso VALIE EXPORT deve ser grafado sempre com letras maiúsculas. 
e depois multiplicada (várias pessoas são vistas em um supermercado portando o mesmo tipo de chapéu).

O recorte de ações apresentado coloca em cheque a ideia de espectador como aquele que aceita o pacto ficcional, como se tal função estivesse restrita apenas àqueles que estão conscientes da construção que se inscreve ou irrompe no contexto urbano. As performances de Maicyra Leão e Eleonora Fabião contam apenas com espectadores passantes. Essas ações ocupam o espaço público, transformando-o em um território de jogo e colocando todo e qualquer passante num potencial espectador. Nos casos de Jiri Kovanda e Laurie Anderson, as ações são testemunhadas por apenas alguns passantes, sendo imperceptíveis para a maioria deles. Em Kovanda, a ação passa-se no meio da multidão, entretanto, não é possível percebêla enquanto ela ocorre; é a partir de sua passagem para outra linguagem, de sua expressão em outra materialidade, que a obra passa a existir. Em Contact, assim como nas demais ações desse artista, o termo infra-mince, cunhado por Marcel Duchamp ${ }^{4}$, é um conceito operatório fundamental, pois possibilita que se discuta a fenomenologia das coisas imperceptíveis. Graças a essa noção, o autor abordou a invisibilidade como uma prática possível e convocou, de maneira indireta, os artistas a buscarem o infra-mince como resposta a um mundo tão sobrecarregado de informações, de ideias, de referências e de imagens impactantes.

Curiosamente, o que tornam visíveis as ações compostas na lógica do infra-mince é a fotografia, o documento decorrente da performance. O que ocorre nesse movimento de reprodução ou representação de ações efêmeras e imateriais em suporte fotográfico é que o arquivo tem uma tendência a se emancipar de seu estatuto puramente documental. Ou seja, ele tem a possibilidade de se tornar um material artístico independente da performance, ainda que seu processo de produção seja profundamente marcado pela experiência vivida. Dessa forma, ação performativa e fotografia convivem como produções paralelas considerando a evolução processual e conceitual da arte desde a década de 1960.

4 Marcel Duchamp escreveu 46 notas sobre esse conceito, entre 1935 e 1945, tendo se dedicado mais a esse assunto que à ideia de ready made, paradoxalmente, seu conceito mais conhecido. 
Em Fully Automated Nikon, os participantes resultam de encontros fortuitos com os passantes da cidade. Em vez de serem escolhidos, revelam-se por meio de suas atitudes e não podem ser considerados "espectadores". Ao se tornarem alvo da câmera Nikon da artista, passam a assumir involuntariamente o papel de jogadores, participantes diretos da ação. Os homens que se relacionam com essa Laurie Anderson armada funcionam como operadores de um jogo socialmente praticado, comum até os dias de hoje, transposto para a esfera da performance. Reinventando sua posição na vida real, a performer parte para a ofensiva, usando sua câmera como dispositivo de produção de provas, de denúncia.

Até então não há indícios de atividade artística; toda essa situação poderia se resumir à militância feminista e experimentação de novas configurações de comportamento para as mulheres. O fato de a performer ampliar as fotografias, inserindo uma tarja branca sobre os olhos dos homens capturados - para preservar minimamente a identidade deles -, e realizar uma exposição com esse material é o que posiciona essa prática da vida cotidiana na esfera artística. Ao trocar de lugar com o agressor, olhando através da câmera, a artista torna-se ela mesma espectadora da ação. Laurie Anderson propõe uma inversão, um outro modo de sociabilidade. Por esse motivo, tal ação será mais bem-sucedida à medida em que seu programa for reperformado, tornando-se acessível a toda e qualquer mulher. Nesse sentido, o que está em jogo não é a autoria da ação, mas a quantidade de mulheres que aderem a essa prática.

Nos quatro últimos casos apresentados (as performances de Jiri Kovanda, Laurie Anderson, VALIE EXPORT e Francis Alÿs), por mais que as ações sejam presenciadas por passantes, elas visam principalmente espectadores ausentes, que entrarão em contato com as performances posteriormente. Mesmo que esses artistas se misturem aos pedestres, sigam seus fluxos e se aproximem dos passantes, propondo outros modos de (con)vivência, o maior número de pessoas que terá acesso a essas ações não está presente. Tais ações se endereçam a um público que acessa os desdobramentos em outro espaço-tempo, vendo as fotos, os vídeos, os desenhos ou as narrativas produzidas a partir dessas experiências. 


\section{Sobre o espectador ausente e a performance endereça- da para a câmera}

Narrativas podem nos levar a compreender. Fotos fazem outra coisa: nos perseguem.

Susan Sontag

À medida que se constata não somente a existência do espectador ausente, mas as proporções que sua atividade toma dentro do campo da performance, muitos autores passam a questionar a hegemonia da documentação sobre a ação em si. Observando os documentos decorrentes das criações dos Acionistas Vienenses, Philip Auslander considera o público inicial da performance irrelevante. Para ele, o que conta é o espectador ausente, aquele que tem acesso ao documento da performance. Portfolio Doggedness é um exemplo de ação vienense, realizada pela única mulher que integrou o grupo no início do movimento.

De acordo com Widrich (2014), a fotografia não apenas reporta um evento, ela concede imagens históricas para nosso imaginário, além de revelar modos de performar para a câmera. Todo esse material contribui igualmente para experimentações que se fazem no presente. Analisando a mesma performance de VALIE EXPORT, cujo nome já ressalta seu caráter de lista ou coleção de imagens (portfólio), a autora revela quanto a artista é consciente do papel dado à documentação. Nesse caso, a câmera não captura apenas a ocorrência do ato, mas a reação do público. Conforme Widrich, há nos projetos colaborativos de EXPORT e Weibel muitas camadas de mediação, literal e metafórica, de tal modo que o material produzido em decorrência da performance constitui-se ele mesmo em ação (lbid., p. 61).

Numa era pré-internet, o portfólio composto por VALIE EXPORT foi amplamente difundido, superando infinitamente o alcance que a ação teve no ato de sua execução. A importância desse alcance não se restringe ao número de visualizações, mas ao impacto que a ação cria sobre diferentes contextos nos quais a visão de um homem de quatro, sendo levado pela coleira, poderia gerar. Por um lado, muitos passantes que se deparam presencialmente com a performance não se envolvem com o que acontece, nem mesmo refletem sobre o que veem; frequentemente, a reação desses espectadores fortuitos é 
o choque, o espanto, não chegando a discutir de maneira aprofundada sobre os temas evocados por aquela visão. Por outro, o portfólio possibilita uma observação mais detalhada não apenas da performance enquanto ação, mas também do contexto no qual ela se inscreve e nas reações que ela provoca. De certo modo, o documento oferece uma visão mais ampla das situações construídas pelos artistas, possibilitando não apenas uma circulação mais dinâmica do material artístico, mas também de outros elementos para que as mesmas sejam analisadas.

A intenção de EXPORT ao documentar a performance ao vivo não é apenas comprovar que a ação realmente ocorreu no espaço público e não num estúdio (atestando que não se trata de uma fotomontagem), mas enfocar a reação dos passantes às suas ações. A opção por estruturar os resquícios de Doggedness em um portfólio revela a intenção de EXPORT de operar em um momento posterior à ação propriamente dita. Ela se vale do portfólio como ferramenta, assim como se vale da documentação em vídeo como meio de dissecar a ação e afirmá-la como um corpo expandido, capaz de ser representativo em diferentes mídias.

Rebecca Schneider, por sua vez, pressupõe que "estamos lendo o arquivo como um ato" (SCHNEIDER apud WIDRICH, 2014, p. 57, tradução da autora). Nesse sentido, argumenta que o documento dá acesso ao passado, estabelecendo uma relação com a história e, portanto, a leitura da performance não deve ser exclusivamente associada ao efêmero, nem baseada em documento, pois a primeira não pode ser dissociada do segundo. Performance e documento são como carne e osso, o que Widrich compara com a relação entre o filme e o celuloide. Do mesmo modo como afirmamos que aquilo que vemos projetado na tela é um filme, o celuloide onde ele se encontra também pode ser considerado filme.

Destaco, pois, a diferença existente entre a câmera que registra um evento e a que interage com o performer. No primeiro caso, ela é sujeito da ação, documenta o que se passa, construindo um discurso. Pode-se dizer que mostra seu ponto de vista sobre a ação observada. A câmera pode, portanto, ser considerada a voz enunciadora, aquela que fabula, que apresenta os fatos.

No segundo caso, a câmera é o objeto da ação do performer. Como o discurso é endereçado a ela, é o performer que dispõe de seu controle, po- 
sicionando-a e tomando todas as decisões a respeito da captação da performance. Em muitos casos, essa tarefa não é realizada por apenas um artista; muitas parcerias entre performers e fotógrafos são seladas com o objetivo de organizar a ação em função do olhar da câmera ou vice-versa. Dessa forma, a câmera torna-se o meio de comunicação do artista, que deixa de organizar um evento para receber o público e passa a organizar outra situação, direcionada para a documentação: a captação da performance.

O direcionamento da performance para a câmera oculta o papel de registro que lhe era inicialmente atribuído e coloca em evidência seu papel de suspensão do tempo e do espaço da ação, deslocando a performance do aqui e agora. Dito de outro modo, ao direcionar a performance para uma câmera, o artista adia o encontro com o outro, deixa de agir diretamente no presente e opera ao mesmo tempo em materialidades distintas. Por mais que a performance se caracterize por uma ação realizada por um corpo no presente, ou pelo simples ato de um corpo se propor a fazer algo, a presença da câmera modifica o corpo e o desloca de seu espaço-tempo inicial. A performance transforma a câmera no outro e o virtualiza, tornando possível se comunicar com corpos de diferentes territórios e temporalidades. Há nessa mudança de enfoque - da câmera que olha para a câmera que é olhada - uma operação que desterritorializa a ação para, em seguida, reterritorializá-la.

A fotografia, nesse sentido, pode ser considerada a fonte primária da performance. Na medida em que a fotografia não se volta mais para o registro do encontro com o espectador, há uma modificação da relação entre performance e público. Quando a performance é endereçada para a câmera, ela passa a prescindir da presença do espectador, pois a execução da ação não coincide necessariamente com a presença do público. Ou então, ela se relaciona diferentemente com quem a presencia (os passantes ocasionais, por exemplo) e com quem está ausente (o espectador pesquisador, potencial, futuro). No caso das performances urbanas, mesmo que a ação prescinda da presença do público, ela se instaura como acontecimento dentro de uma espaço-tempo já habitado. A cidade não se esvazia para que a performance se inscreva nela. Os modos de intervir no contexto urbano são complexos, diversificados e capazes de instaurar situações variadas de sociabilização, de comunicação e de visibilidade. Essa profusão de plataformas de conta- 
to, compostas de diferentes dispositivos fabricadores de imagem e de som, criam outras qualidades de presença.

É como se o espectador se caracterizasse por um efeito de presença, pois a execução da performance não será necessariamente concomitante à sua recepção. Mediante o adiamento da recepção, a fotografia, o vídeo e outras materialidades distintas daquelas associadas às artes efêmeras e imateriais ganham relevância no campo da performance e das artes da cena. Não se trata de transmitir uma performance ao vivo, via streaming, para um espectador virtualmente presente. Nos casos tratados aqui, a performance realiza-se para um público ausente e não apenas virtual. Trata-se de alguém que entrará em contato com a ação futuramente, sem que o artista estabeleça qualquer grau de convivência com esse espectador. A performance se torna ela mesma um processo de produção de visões e reflexões para o futuro. Desconectada da presença física do público, a performance assume-se também como um retrato do tempo vivido, um cartão postal para o futuro.

Sendo assim, é possível afirmar que a câmera, em diversos casos, substitui a presença concreta e imediata do espectador. Os artistas passam a endereçar suas ações para a câmera, cuja presença modifica a ação realizada. É o que acontece com Reenactement, de Francis Alÿs, artista que consegue inserir os policiais que o detiveram no remake de sua ação, fazendo dos dois vídeos realizados com e sem a participação da polícia as resultantes diretas de sua performance. Portar uma câmera na rua é dispor de um dispositivo não apenas associado ao registro, mas igualmente associado ao controle, à segurança e à defesa. Embora a grande maioria das pessoas atualmente tenha uma câmera em seu telefone celular, quem porta esse dispositivo em um espaço público ainda detém um tipo de poder. Essa presença modifica o modo das pessoas agirem, pois elas se sentem vigiadas e, como afirma Roland Barthes, "objetificadas", como se o olhar da câmera transformasse o sujeito em objeto. "[...] para dizer a verdade, não sou nem um sujeito nem um objeto, mas antes um sujeito que se sente tornar-se objeto: vivo então uma microexperiência da morte (do parêntese): torno-me verdadeiramente espectro" (1984, p. 27). Ainda sobre o desconforto de estar diante de uma câmera, o autor afirma que diante de uma objetiva, ele não sabe como do interior dele mesmo agir sob sua pele. 
[...] a partir do momento que me sinto olhado pela objetiva, tudo muda: ponho-me a 'posar', fabrico-me instantaneamente um outro corpo, metamorfoseio-me antecipadamente em imagem. Essa transformação é ativa: sinto que a Fotografia cria meu corpo ou o mortifica, a seu bel-prazer. (Ibid., p. 22)

Esse deslocamento do espectador presencial para a câmera ganha um impulso ainda maior com o advento da internet. A maioria dos estudos de performance acontecem a partir de bases de dados e buscas na web, sem que tal experimentação tenha sido presenciada fisicamente pelo pesquisador. Em 1997, Amelia Jones é convidada para escrever um artigo para a revista Art Journal e nota que é a única pesquisadora que não presenciou as ações que analisou. Ao constatar que a edição da revista se voltava para a importância de presenciar efetivamente uma performance como forma de melhor apreender sua história, a autora questiona esse posicionamento, colocando o testemunho e o historiador em pé de igualdade. Para justificar a atitude provocadora, Jones afirma que tanto aquele que testemunha, quanto o historiador, devem interrogar o passado com suficiente distanciamento e, para isso, ambos precisam recorrer a documentos. Endossando sua argumentação, a pesquisadora ressalta a dissolução de seus objetos de estudo e o olhar crítico destinado à possível documentação. Se dependesse de ter assistido às performances que compõem o corpus de sua pesquisa para estudá-las, não teria idade suficiente para tê-las frequentado (entre 3 e 15 anos). Ela afirma ter iniciado seus estudos nesse campo somente aos 30 anos, portanto não poderia ter tido acesso presencialmente a tais performances.

A partir desse dado autobiográfico, a autora de "Presence in absentia: experiencing performance as documentation" defende o uso da documentação em performance como uma fonte legítima de estudo e análise dessas ações. Jones apresenta duas acepções de performance art: uma mais ampla, que remonta ao dadaísmo e considera performance qualquer exploração de teatralidade da parte de um artista visual; e outra mais estreita, que considera performance algo que ocorre diante de um público. A essas acepções, a autora contrapõe a noção de body art ou bodywork, modalidade que independe da presença de espectadores, e dessa forma ela não considera a presença do público uma premissa para a realização de uma performance. 
Quando uma performance se dirige a uma câmera, o resultado foto ou videográfico - isto é, sua documentação - ganha outra dimensão, cumpre outro papel no campo da performance. Não se trata apenas de um registro, mas de um atestado da existência da ação, um meio de expressão, uma extensão, um prolongamento da performance em outras materialidades. Parafraseando Susan Sontag, que afirmava que, quando há fotos, uma guerra se torna real (SONTAG, 2005, p. 87), podemos afirmar que a fotografia faz o mesmo com a performance: ela atribui à ação um certificado de existência, de realidade. É assim que o ato de documentar passa a integrar o ato de performar. Se tomarmos como referência a acepção de Richard Schechner, a performance pode ser compreendida a partir de três operações: ser/estar (being), ou seja, se comportar (to behave); fazer (doing), como a atividade de tudo o que existe; e mostrar o que se faz (showing doing), que consistiria em dar-se em espetáculo, em mostrar ou se mostrar (SCHECHNER, 2006, p. 28). Nesse contexto, o "mostrar" aferido por Richard Schechner desloca-se do público para a câmera. Ou seja, se anteriormente o estatuto de uma performance era definido pela presença de uma audiência, a partir da expansão desse campo para outras materialidades, é a presença de câmera que passa a definir tal estatuto.

Conforme Roland Barthes, a fotografia anuncia uma ausência; ela se apresenta onde o sujeito já não está ou no lugar onde ele não alcança. O autor defende que a fotografia "desrealiza completamente o mundo humano dos conflitos e dos desejos, sob o pretexto de ilustrá-lo"(1984, p. 174). Pensando em termos de performance, a fotografia proveniente dessa ação não apenas ilustra, mas testemunha sua realização. No entanto, esse suporte ainda assim anuncia a ausência do ato, prorrogando o encontro com o espectador, que será, ele sim, separado do evento. Quando alguém tem acesso a uma performance via fotografia, essa pessoa está necessariamente à parte do evento. Ela acessa os rastros, os vestígios, sem no entanto sentir os cheiros, observar o antes e o depois, ou as interações precisas estabelecidas com um ou outro espectador. O documento não permite tampouco que o espectador se confunda com aquilo que acontece, ele permanece de fora. Nesse mesmo sentido, Barthes afirma que não pode "aprofundar, penetrar a Fotografia. Posso apenas varrê-la com o olhar, como uma superfície imóvel. A Fotografia é chã, em todos os sentidos da palavra [...]" (Ibid., p. 157). E acrescenta, citando Maurice Blanchot: 
[...] a essência da imagem é estar toda fora, sem intimidade, e no entanto mais inacessível e misteriosa do que o pensamento de foro íntimo; sem significação, mas invocando a profundidade de todo sentido possível; irrevelada e todavia manifesta, tendo essa presença-ausência que faz a atração e o fascínio das Sereias. (BLANCHOT apud BARTHES, 1984, p. 157)

Se a noção de performance quando se aproxima da body art é associada à entrega do corpo do artista sem mediação, sem intermediários, à relação com o público, tomando o corpo como material primário, Amelia Jones, em texto supracitado, rejeita tais princípios. A ideia de que a performance ou a body art seja a única forma de arte capaz de garantir a presença do artista, pois coloca sua vida real e suas experiências em jogo, suprimindo a mediação e colaborando para a exaltação do "status da representação" em vez de confirmar sua prioridade ontológica (JONES, 1997, p. 13).

Os aspectos representacionais deste trabalho - seu "jogo dentro da arena do simbólico" e, eu acrescentaria, sua dependência da documentação para atingir status simbólico dentro do âmbito da cultura - expõem a impossibilidade de atingir pleno conhecimento de si por meio da proximidade do corpo. Ter contato físico direto com uma artista que puxa um pergaminho de seu canal vaginal não garante mais conhecimento de sua subjetividade ou intencionalidade do que assistir um filme ou observar uma imagem dessa atividade, ou ainda olhar uma pintura feita como resultado de tal ação (Ibid., tradução da autora).

Jones refere-se no trecho anterior à conhecida performance de Carolee Schneemann, Interior Scroll, de 1975, para destacar a insuficiência do corpo na articulação de seus significados, pois dependem do contexto no qual ele se expõe, do intercâmbio entre artista e espectadores, bem como do ato de documentar a ação. Nesse sentido, a fotografia seria considerada como um suplemento do corpo do artista, tanto como prova visível de sua existência quanto como prolongamento sem fim.

A autora vale-se das ideias de Derrida para afirmar que o suplemento representa uma ameaça, pois indica uma falta, uma ausência. De modo similar ao que afirma Barthes, para Derrida, o suplemento também se configura como a primeira e mais eficiente proteção contra essa ameaça. Na defesa dos suplementos, o autor afirma que a body art - leia-se, performance - iniciou uma 
corrente infinita derivada do corpo em si, como a narrativa falada, a fotografia, o vídeo e outros textos, como forma de explicar o equívoco da centralidade do corpo no discurso artístico modernista e pós-modernista. O que Jones irá defender a partir das ideias de Derrida é que a body art exacerba a suplementaridade do corpo do artista, cuja exposição não é garantia de presença. O corpo complementa o evento da performance e cumpre seu papel de representação dentro da arena do simbólico. "Ao invés de confirmar a coerência ontológica do corpo-como-presença, a body art depende da documentação, confirmando - e até mesmo exacerbando - o caráter suplementar do corpo em si” (Ibid., p. 15, tradução da autora). Dessa maneira, Jones considera que a body art não expõe o corpo apenas no momento da comunicação e da troca com o público, mas também por meio dos diferentes modos de (re)apresentá-lo.

Tendo em vista o caminho traçado pelo espectador, de princípio ativo do jogo até o momento em que se configura como ausência, quando o corpo é considerado suplemento, resgato Mechtild Widrich para tentar equiparar a ação em si ao prolongamento da performance em outras materialidades. Para a autora, o público inicial é tão importante para a experimentação de "um ato anárquico" em local comum, provavelmente público, quanto a produção de vestígios é constitutiva do ato performativo. Nessa perspectiva, não se trata nem de eliminar o evento enquanto situação de encontro, nem de deixar de produzir materialidades distintas da efemeridade da performance. É como se a ação precisasse de produções paralelas para concretizar seu caráter imaterial e colocar a presença e o documento, o efêmero e o permanente em condição de equidade. Amelia Jones, por sua vez, considera o acesso aos restos da performance tão ou mais intrigante do que a frequentação da performance ao vivo. Quando se estuda performance, o retorno ao material é quase obrigatório. Mesmo tendo presenciado a ação, faz-se necessária a consulta aos arquivos, pois eles são pistas deixadas pelo artista.

Alterar o estatuto do espectador corresponde a uma alteração na postura do artista, que se coloca como um criador de dispositivos ou propositor de experiências, e não como alguém que dispõe de capacidades extraordinárias. Ele abdica do papel de virtuose e categorias frequentemente consideradas indispensáveis para a produção artística, como a ideia de talento, são diluídas. O foco desloca-se da exibição para o compartilhamento, que pode 
acontecer em múltiplas instâncias, seja no ato mesmo do acontecimento cênico - quando os espectadores também acionam a criação -, seja a posteriori, por meio de outras materialidades decorrentes da ação performática. Desse modo, todos podem usufruir e experimentar proposições artísticas que se configuram abertas, inclusivas e inacabadas, por serem altamente dependentes do encontro com o outro. À medida que se reorganiza os modos de fazer, redefine-se também os modos de usar, ou seja, a toda modificação no fazer artístico, corresponde uma modificação no modo do espectador se relacionar e usufruir do teatro e da performance.

\section{Referências bibliográficas}

BARTHES, R. A câmara clara. Rio de Janeiro: Nova Fronteira, 1984.

BOURRIAUD, N. Esthétique relationnelle. Monts: Les presses du réel, 1998.

CARERI, F. Walkscapes: o caminhar como prática estética. São Paulo: G. Gili, 2013. FERNANDES, S. Teatralidade e performatividade na cena contemporânea. Repertório, Salvador, n. 16, p.11-23, 2011.

JONES, A. Presence in absentia. Experiencing performance as documentation. Art Journal, v. 56, n. 4, p. 11-18, 1997. Disponível em: <http://art.usf.edu/file_uploads/ presence.pdf $>$. Acesso em: 5 dez. 2016.

LUCET, S. Mémoires et pouvoirs du spectateur. Théâtre Public - Penser le spectateur, Montreuil, n. 208, p. 98-102, abr.-jun.2013.

RANCIĖRE, J. O espectador emancipado. São Paulo: Martins Fontes, 2012. Les scènes de l'émancipation: entretien avec Jacques Rancière. Théâtre

Public: penser le spectateur, Montreuil, p. 8-15, abr.-jun. 2013.

SCHECHNER, R. Performance studies: an introduction. New York : Routledge, 2006. SONTAG, S. Diante da dor dos outros. São Paulo: Companhia das Letras, 2005. VELOSO, V. Percorrer a cidade a pé: ações teatrais e performativas no contexto urbano. Tese (Doutorado) - Escola de Comunicação e Artes, Universidade de São Paulo, São Paulo, 2017.

WIDRICH, M. Performative monuments: The rematerialisation of public art. Manchester: Manchester University Press, 2014.

Recebido em 24/04/2017 Aprovado em 02/05/2017

Publicado em 17/07/2017 